\title{
O PROGRAMA NACIONAL DO LIVRO DIDÁTICO E O PROCESSO DE CONSTITUIÇÃO DE UMA DIDÁTICA DA HISTÓRIA PARA OS ANOS INICIAIS
}

\author{
THE NATIONAL PROGRAM OF THE DIDACTIC BOOK AND THE PROCESS OF \\ CONSTITUTION OF A HISTORY DIDATICS FOR THE INITIAL SERIES
}

Tiago Costa Sanches ${ }^{1}$

\begin{abstract}
RESUMO: Nos percursos de constituição da Didática da História nos anos iniciais, diversas concepções de ensino-aprendizagem da História pautaram os debates sobre o tema, conferindo, a esta Didática, um caráter epistemológico específico. Preocupada em investigar os processos de construção do conhecimento histórico, utilizando a epistemologia específica da História, a linha de pesquisa Educação Histórica, apresenta, hoje, uma possibilidade de se pensar a Didática da Histórica a partir da própria ciência de referência. O presente estudo contou com uma investigação empírica a partir da abordagem metodológica denominada Análise de Conteúdo e procurou investigar em guias de livro didático, referentes ao Programa Nacional do Livro Didático (PNLD), quais concepções de ensino-aprendizagem balizaram sua construção e orientações. Deste estudo teórico e das análises, podese verificar alguns pressupostos e significados de uma Didática da História para os anos primeiros anos do Ensino Fundamental.
\end{abstract}

Palavras-chave: PNLD. Educação histórica. Didática da história. Anos iniciais.

\begin{abstract}
In the course of the formation History Didactics in the initial years, many conceptions of History teaching and learning guided the debates on the theme, conferring to this Didactics a specific epistemological character. Concerned about investigating the processes of construction of historical knowledge, using the specific epistemology of History, the line of research History Education, presents today a possibility of thinking the History Didactics from its own science of reference. The present study had an empirical investigation, based on the methodological approach called Content Analysis and sought to investigate in textbook guides regarding to the National Program of Didactic Book (PNLD), which conceptions of teaching and learning were its building blocks and orientations. From this theoretical study and analysis, we can verify some assumptions and meanings of History Didactics for the first years of elementary school.
\end{abstract}

\footnotetext{
${ }^{1}$ Professor da Universidade Federal da Integração Latino Americana - UNILA.
} 
Keywords: PNLD. History education. Didactics of history. Initial series.

\section{Introdução}

A presente obra é fruto de um crescimento significativo de pesquisas de domínios específicos na área do Ensino de História, referentes ao chamado campo da Educação Histórica. Este campo de investigação se desenvolveu em países como Inglaterra, Alemanha, Estados Unidos, Canadá, Espanha, Portugal e, mais recentemente, no Brasil. Uma prerrogativa destas pesquisas é a utilização da epistemologia específica da História nos processos de pesquisas, buscando nas discussões da Ciência da História os princípios teóricos que orientam o percurso investigativo. Estas discussões sobre aprendizagem histórica a partir da própria ciência de referência vêm sendo feitas sistematicamente em programas de pósgraduação, cursos de formação continuada, eventos da área e, particularmente, no âmbito de experiências desenvolvidas no Laboratório de Pesquisa em Educação Histórica (LAPEDUH) da Universidade Federal do Paraná desde 1997.

$\mathrm{Na}$ esteira das reflexões precipitadas pelas pesquisas na área da Educação Histórica este trabalho busca responder, a partir dos resultados obtidos na tese de doutoramento ${ }^{2}$, como se deu o processo de constituição de uma didática da História dos anos iniciais a partir da análise de documentos oficiais. Neste sentido, a pesquisa de doutoramento adotou como objeto de análise os documentos oficiais nacionais, responsáveis pela construção teórica e prática, da concepção de aprendizagem histórica presente nos ambientes de formação dos professores e nos processos de efetivação destas propostas em sala de aula. Neste trabalho em especial, será tomado como objeto de análise apenas um fragmento dos documentos analisados na construção da tese de doutoramento, portanto, este artigo objetiva apresentar o processo de construção das concepções de

\footnotetext{
2SANCHES, Tiago Costa Sanches. Percursos da didática da história para os anos iniciais no Brasil. Tese (doutorado em Educação) UFPR, Curitiba, PR, 2015. https://lapeduh.files.wordpress.com/2014/10/tiago-costa-sanches.pdf
} 
aprendizagem histórica presentes na construção e orientações dos Guias do Programa Nacional de Livro Didático de 1997 a 2007.

Para a análise dos documentos oficiais, a metodologia utilizada para a pesquisa empírica foi pautada na análise de conteúdo, proposta pela pesquisadora Maria Laura P. B. Franco, em sua obra de "Análise de conteúdo" (FRANCO, 2005). Neste trabalho a autora busca ampliar a discussão acerca da Análise de Conteúdo e, para isso, evidencia a importância de suas bases teóricas e metodológicas no contexto investigativo. Nesta perspectiva metodológica, o procedimento de pesquisa se situa em um delineamento mais amplo da teoria da comunicação e tem como ponto de partida a mensagem. A metodologia de investigação envolve três momentos distintos no trato com o documento, a análise, a interpretação e a inferência. Considerando a proposta metodológica de Franco (2005), investigar o contexto histórico social da produção de um documento é um importante momento de sua análise já que esta pode explicitar a complexidade do material analisado que envolve. Assim, toda a análise de conteúdo implica em comparações contextuais.

As categorias que estruturaram as análises foram determinadas por aspectos verificados nos documentos, em incursões prévias, que expressassem indicativos teóricos e metodológicos de uma didática específica para os anos iniciais. Verificou-se nos documentos analisados que os pressupostos desta didática foram compostos de três categorias norteadoras, sendo elas o que ensinar; como ensinar e por que ensinar História, entendendo que estas categorias foram formuladas a título de análise, ou seja, não existe esta divisão na estrutura dos documentos.

\section{O Programa Nacional do Livro Didático (PNLD)}

Desde 1929, o Estado brasileiro apresenta uma preocupação com a produção de materiais didáticos que serão utilizados nas escolas. Com a criação do Instituto Nacional do Livro (INL) durante o Governo Vargas, por iniciativa do então ministro Gustavo Capanema, de 1937 (pelo Decreto-Lei no 93, de 21/09/1937), o Estado brasileiro objetivava legalizar o Livro 
Didático e incentivar a sua produção, por meio da elaboração de uma enciclopédia e dicionário da língua brasileira que retratasse a identidade e a memória nacional, além de apoiar a implantação de bibliotecas públicas em todo o Brasil. Mais tarde, com a criação da Comissão Nacional do Livro Didático (CNLD), foi inaugurada, no Brasil, a primeira política de controle sobre a produção de livros didáticos.

A partir do ano de 1971, em substituição à Comissão do Livro Técnico e Didático (COLTED), o Programa do Livro Didático para o Ensino Fundamental (PLIDEF) passa a ser novamente responsabilidade do Instituto Nacional do Livro (INL), que assume as atribuições administrativas e de gerenciamento dos recursos financeiros destinados à produção dos livros didáticos.

Em 1976, com a extinção do INL o governo retoma o processo de compra e distribuição da grande maioria dos livros destinados às escolas das unidades federadas. Os recursos destinados à compra e distribuição dos Livros Didáticos era oriundo do Fundo Nacional de Desenvolvimento da Educação (FNDE) e das contribuições estabelecidas para participação das Unidades da Federação no programa. Devido o crescimento do número de matrículas e da escassez de recursos para atender todos os alunos do ensino fundamental da rede pública, a grande maioria das escolas municipais é excluída do programa.

Em 1983, com a criação da Fundação de Assistência ao Estudante (FAE), o PLIDEF foi incorporado as suas atribuições e surge como proposta a participação dos professores na escolha dos livros e a ampliação do programa, com a inclusão de todas as séries do ensino fundamental.

Em pleno processo de redemocratização o Estado brasileiro iniciou, em1985, em substituição ao PLIDEF, a criação e desenvolvimento do Programa Nacional do Livro Didático (PNLD), tendo como função avaliar, indicar, comprar e distribuir livros didáticos para as escolas públicas. Impulsionado pela busca de critérios de seleção dos materiais didáticos, o governo brasileiro traçou um projeto educacional em torno desta escolha. Era, portanto, imprescindível que os livros se adequassem às propostas 
oficiais de ensino, do contrário não seriam indicados, diminuindo, assim, seu público e seu lucro.

Na década de 1990, houve uma ação institucional de descentralização da seleção dos livros didáticos a serem encaminhados às escolas. A partir de 1995, o PNLD reconfigurou-se, por meio de um processo de avaliação em que uma equipe de especialistas de cada área passou a analisar as diferentes coleções e fazer pareceres sobre os livros inscritos para este PNLD. No ano seguinte, com a criação do10 Guia de Livros Didáticos, foi iniciado o processo de avaliação pedagógica dos livros inscritos para o PNLD 1997.

De acordo com o Fundo Nacional da Educação (FNDE) ${ }^{3}$, o Programa Nacional do Livro Didático (PNLD) tem por objetivo prover as escolas públicas de ensino fundamental e médio com livros didáticos e acervos de obras literárias, obras complementares e dicionários. O PNLD é executado em ciclos trienais alternados. Assim, a cada ano o FNDE adquire e distribui livros para todos os alunos de determinada etapa de ensino, além de repor e complementar os livros reutilizáveis para outras etapas.

Um edital especifica todos os critérios para inscrição das obras. Os títulos inscritos pelas editoras são avaliados pelo Ministério da Educação (MEC), que elabora o Guia de Livro Didático, composto das resenhas de cada obra aprovada, o qual é disponibilizado às escolas participantes pelo FNDE.

A partir destas exigências do MEC, foram produzidos pelo governo federal os Guias de Livro Didático contendo critérios de seleção e aprovação dos livros didáticos de História para os anos iniciais. A partir da estrutura dos documentos, critérios e avaliações realizadas pelos guias serão construídas as análises que busque compreender a concepção de aprendizagem histórica e quais elementos teóricos fundamentam a produção destes documentos.

O Estado brasileiro tem investido, nas últimas décadas, substancialmente, na produção e distribuição destes materiais nas escolas de todo o país. A promoção de medidas e de uma política pública,

${ }^{3}$ Disponível em: http://www.fnde.gov.br/programas/programas-do-livro. Acesso em: 17 set. 2018. 
atualmente conhecida como Programa Nacional de Livros Didáticos (PNLD), voltada para a avaliação, compra e distribuição de livros didáticos a todas as escolas públicas brasileiras, demonstra o interesse do Estado em tornar o livro didático um dos principais instrumentos pedagógicos auxiliares do processo de ensino-aprendizagem.

Nesta nova configuração de avaliação dos livros didáticos, implementada pelo governo federal, a principal particularidade do processo é a atuação de especialistas de cada área. Nesta perspectiva as avaliações seriam submetidas a critérios elaborados por equipes de especialistas ligados ao universo acadêmico interferindo, assim, no perfil dos materiais didáticos a serem produzidos pelas editoras. Ao submeter as obras a outro perfil de avaliação decorrente da participação destes especialistas, os professores também foram afetados em face das modificações das políticas sobre o livro didático.

Com a inserção dos especialistas no processo de avaliação dos materiais didáticos, os guias produzidos pelo PNLD, além de refletirem a ação reguladora do Estado na escolha dos livros a serem utilizados pelos professores em sala de aula, apresentam uma relação entre o conhecimento academicamente produzido e o universo escolar. Esta relação se dá na medida em se propõe um diálogo entre sujeitos originários de espaços diversos, como a academia e a escola.

Portanto, considerando a diversidade de sujeitos que atravessam esta política de avaliação, busca-se investigar a dimensão epistemológica deste processo, tomando, a partir dos critérios de avaliação, suas relações com o campo da Didática da História nos anos iniciais e com o contexto de execução da avaliação dos livros didáticos.

A partir de 1997, com a criação dos PCN's e dos Guias de Livro Didático, observa-se uma tentativa de renovação na perspectiva de ensino e aprendizagem histórica no cenário educacional brasileiro. Portanto, serão tomados como objeto de análise os guias de livro didático voltados para a disciplina de História nos anos iniciais, a partir de 1997, estendendo-se ao ano de 2008, contemplando dez anos de análise documental. 


\section{A relação conteúdo forma para o PNLD}

O Programa Nacional do Livro Didático (PNLD) é fruto de um contexto histórico permeado por influências políticas, econômicas e culturais. Assim, como os Parâmetros Curriculares Nacionais (PCN's) e demais documentos norteadores da Educação, o Programa Nacional do Livro Didático (PNLD) e seus referidos Guias de Livro Didático, surgem como um marco epistemológico educacional, pois apresentava em seu projeto uma nova perspectiva de Educação. Desta forma, a escolha destes Guias de Livro Didático para composição do corpus de análise da presente pesquisa se justifica pela relevância destes materiais na constituição de uma Didática da História nos anos iniciais.

Apesar das discussões sobre a formulação dos critérios gerais de avaliação ${ }^{4}$ precederem a publicação do primeiro Guia do Livro Didático, é em seu texto de apresentação pública que se pode analisar, interpretar e inferir quais concepções teóricas influenciaram sua construção.

Assim, sendo a análise dos documentos referidos concebida a partir da metodologia da Análise de Conteúdo, buscou-se, a partir de categorias construídas no percurso investigativo, compreender quais foram às concepções de ensino-aprendizagem presentes nos documentos analisados.

No trato com os objetos de análise, realizado no percurso investigativo deste trabalho, notou-se que a construção das concepções de ensinoaprendizagem, ou seja, a perspectiva de Didática da História nos anos iniciais, presente nos documentos, estavam pautados em três questões centrais, sendo elas: O que ensinar; como ensinar e por que ensinar.

A partir da construção destas categorias de análise, pode-se verificar quais elementos teóricos e metodológicos constituíram a formação de uma didática específica para os anos iniciais. Portanto, foram realizadas análises dos Guias de Livro Didático (1997-2007) tendo estas três questões como categorias estruturantes.

Neste sentido, buscou-se comparar, a partir das categorias estruturantes, os critérios de avaliação dos livros didáticos presentes nos

${ }^{4}$ Os critérios de avaliação do Livro Didático foram produzidos no ano de 1995 pelo Programa Nacional do Livro Didático (PNLD). 
Guias de 1997/1998, 2001, 2004 e 2007. Portanto, os documentos, a partir dos critérios de avaliação, apresentam os aspectos que dizem respeito à produção/construção de conhecimentos históricos, neste sentido observase, o que ou quais conteúdos históricos os livros didáticos devem conter na disciplina de História.

Procurou-se ressaltar, nesta análise dos critérios de avaliação dos Guias de Livro Didático, elementos que explicitassem os aspectos referentes ao processo de ensino-aprendizagem da História.

Os Guias não foram transcritos na integra, pois se buscou analisar apenas os fragmentos que apresentassem, em seu texto, aspectos constituintes de uma Didática da História nos anos iniciais. Já na Introdução do Guia de 1997, o documento apresenta a finalidade do Ensino de História:

\begin{abstract}
O objetivo central da história é a formação do cidadão, como indivíduo situado historicamente, consciente da sua dimensão social, no seu tempo, e capaz de entender e analisar a dinâmica das organizações sociais, cuja influência se exerce - em diferentes locais e momentos - sobre os mais variados aspectos da vida cotidiana, e também sobre os diferentes processos históricos. Esse objetivo se concretiza mediante a aquisição de um conjunto de conhecimentos, fundados em conceitos como os de tempo, espaço, cultura, sociedade, relações sociais, poder, trabalho e natureza. (BRASIL, 1996, p. 129).
\end{abstract}

Segundo o documento, a aprendizagem histórica possibilita a formação de um cidadão consciente de sua condição social e temporal. Cabe ressaltar a categoria vida cotidiana como espaço de experiência dos sujeitos históricos.

Esta aprendizagem se consolida mediante a aquisição de conhecimentos - conceitos históricos. Neste sentido, o documento indica $\boldsymbol{o}$ que deveria se aprender, ou seja, ao aprender os conceitos de tempo, espaço, cultura, sociedade, relações sociais, poder, trabalho e natureza os alunos estariam sendo formados para a vida em sociedade.

Em relação aos conteúdos trabalhados, o Guia de 2000 argumenta que os conhecimentos históricos são construídos a partir de regras e princípios próprios desta ciência. Assim sendo, o documento ressalta a importância de verificar se a coleção de livros didáticos, na exposição dos conteúdos 
específicos, mostrou-se em sintonia com as metodologias próprias da disciplina História.

Em seguida o Guia elenca os conceitos centrais para o desenvolvimento da aprendizagem histórica. São eles: tempo, espaço, história, sujeito histórico, cultura, natureza, sociedade, relações sociais, poder, trabalho. (BRASIL, 2000).

O documento indica que estes conceitos necessitam de algumas habilidades para que sejam aprendidos. São elas: a noção de período, seqüência, transformação, passado, presente, futuro, simultaneidade e duração. (BRASIL, 2000).

Na edição seguinte, o Guia de Livro Didático (BRASIL, 2004, p.34) orienta que os livros de História devem explicitar as propostas metodológicas relativas ao conhecimento histórico, considerando-se a variedade das tendências historiográficas existentes na área. Ainda assim, os livros devem manter a coerência entre as propostas e a exposição dos conteúdos, em forma de textos e de atividades.

Outro critério elencado pelo Guia de 2004 foi analisar se os livros avaliados apresentaram um trabalho adequado com a historicidade dos conceitos, evitando-se anacronismos e nominalismos ${ }^{5}$.

Os documentos propõem a verificação dos livros a partir da forma como os autores utilizaram as categorias centrais do conhecimento histórico: tempo, espaço, sujeito histórico, cultura, natureza, sociedade, relações sociais, poder, trabalho, período, sequência, transformação, passado, presente, futuro, simultaneidade, duração. Por último, as obras foram avaliadas quanto à presença de estereótipos e de simplificações explicativas que banalizam o conhecimento e prejudicam a formação de cidadãos críticos e conscientes.

O Guia de 2007 apresenta em seus princípios Históricos a importância de se adequar a historicidade dos conceitos utilizados às categorias centrais

\footnotetext{
${ }^{5} \mathrm{O}$ anacronismo, que consiste em atribuir aos homens do passado nossas próprias razões ou sentimentos, interpretando a Historia em função de critérios inadequados, validos para outras épocas. O voluntarismo, que consiste em aplicar uma teoria a priori sobre documentos e textos, em função do que se quer demonstrar. O nominalismo, quando a analise proposta abstrai-se de realidades vividas pelos sujeitos históricos, em proveito da mera descrição de quadros jurídicos, regulamentares ou institucionais.
} 
do conhecimento histórico: tempo, espaço, sujeito histórico, cultura, natureza, sociedade, relações sociais, poder, trabalho, período, seqüência, transformação, passado/presente/futuro, simultaneidade e duração.

Quadro 1 - Comparativo Dos Conceitos Históricos (PNLD 1997-2007)

\begin{tabular}{|c|c|}
\hline Documentos & Conceitos a serem aprendidos \\
\hline Guia de 1997 & $\begin{array}{l}\text { tempo, espaço, cultura, sociedade, relações sociais, poder, } \\
\text { trabalho e natureza }\end{array}$ \\
\hline Guia de 2000 & $\begin{array}{l}\text { tempo, espaço, história, sujeito histórico, cultura, natureza, } \\
\text { sociedade, relações sociais, poder, trabalho }\end{array}$ \\
\hline Guia de 2004 & $\begin{array}{l}\text { tempo, espaço, sujeito histórico, cultura, natureza, sociedade, } \\
\text { relações sociais, poder, trabalho, período, sequência, } \\
\text { transformação, passado, presente, futuro, simultaneidade, } \\
\text { duração }\end{array}$ \\
\hline Guia de 2007 & $\begin{array}{l}\text { tempo, espaço, sujeito histórico, cultura, natureza, sociedade, } \\
\text { relações sociais, poder, trabalho, período, sequência, } \\
\text { transformação, passado/presente/futuro, simultaneidade e } \\
\text { duração. }\end{array}$ \\
\hline
\end{tabular}

Fonte: Brasil (1997, 2000, 2004, 2007).

A partir de uma análise comparativa entre os documentos, verifica-se que os Guias de Livro Didático ressaltam a importância de verificar se as coleções de livros didáticos avaliadas apresentaram sintonia com as correntes historiográficas e com as metodologias próprias da disciplina História na exposição dos conteúdos específicos.

Com exceção da primeira edição, todos os Guias apresentam, em seus critérios avaliativos, a necessidade de se pensar a historicidade dos conceitos de tempo, espaço, história, sujeito histórico, cultura, natureza, sociedade, relações sociais, poder, trabalho, evitando, assim, os anacronismos e nominalismos na construção dos conhecimentos históricos.

Aliados aos conceitos expostos acima, os critérios indicam que os livros deveriam estimular as noções de período, sequência, transformação, passado, presente, futuro, simultaneidade e duração, entendidas nesta edição como habilidades. A partir do Guia de 2004, estas habilidades são incorporadas aos conceitos utilizados como categorias centrais do conhecimento histórico. 
Nota-se, no decorrer das edições, uma transformação/adequação nas orientações sobre os conteúdos históricos a serem trabalhados nos livros didáticos nos anos iniciais, no entanto, os Guias admitem que cada coleção possui liberdade para escolher a corrente historiográfica que melhor a represente, os documentos, por meio de critérios de avaliação, limitam os editores a seguir uma concepção de conhecimento histórico prédeterminada.

Dentre as categorias de análise das concepções de aprendizagem histórica, presentes nos Guias de Livro didático, o aspecto referente a como ensinar, foi o mais esclarecedor. Verificou-se, claramente, nas análises, uma distinção dentre os diferentes aspectos da aprendizagem histórica.

Os conteúdos ou conceitos históricos foram elencados, segundo os documentos, a partir de critérios próprios da Ciência da História. No entanto, o documento de 1997 ressalta que esses conceitos históricos não podem ser estudados isoladamente. Portanto, estes conhecimentos históricos devem ser trabalhados nas escolas, a partir de princípios pedagógicos que organizam, metodologicamente, 0 ensino e a aprendizagem destes conteúdos.

Segundo o Guia de 1997, um destes princípios metodológicos é que a aprendizagem deve partir do estudo do meio em que o aluno está inserido, ou seja, é preciso estabelecer um contexto que unifique o ensino da História e da Geografia, já que estas disciplinas estão inseridas na área denominada Estudos Sociais.

A partir do princípio exposto acima, o documento apresenta os critérios relativos ao conhecimento da área de História e os conhecimentos relativos aos aspectos pedagógico-metodológicos. Os critérios de avaliação do guia, relativos aos conhecimentos da área do conhecimento, indicam que:

É fundamental que o livro não contenha informações erradas nem desatualizadas. Deve existir perfeita articulação entre os conhecimentos das disciplinas da área e também entre os desta e os das demais áreas. Essa articulação é importante para a compreensão do conteúdo e para o desenvolvimento de habilidades, com o a capacidade de estabelecer relações entre fatos e entre situações, envolvendo diferentes sujeitos, em diferentes locais e momentos. (BRASIL, 1996, p.130). 
Verifica-se, neste critério, uma preocupação do documento em avaliar a cientificidade das informações contidas nos livros didáticos. Além disto, é ressaltada a importância da articulação entre os conhecimentos da área de História e a relação deste conhecimento com as outras disciplinas. Pode-se perceber neste critério uma indicação de como se ensina História, ou seja, o ensino da disciplina requer a articulação entre os conhecimentos conceitos históricos - entre si e entre outros conhecimentos de outras disciplinas.

No que se refere aos critérios de análise, relativos aos aspectos pedagógico- metodológicos, foram considerados nas avaliações os seguintes aspectos: "a formação de conceitos e o desenvolvimento de habilidades, o desenvolvimento da linguagem e as atividades e exercícios propostos" (BRASIL, 1996, p. 131).

No critério seguinte relativo à formação de conceitos e desenvolvimento de habilidades, o documento indica como os conteúdos devem ser apresentados e quais suas contribuições na formação dos alunos.

\begin{abstract}
Os conteúdos devem ser adequados ao desenvolvimento cognitivo do aluno, considerando seu repertório, sua experiência e seu cotidiano; e contribuindo efetivamente para a formação de idéias e conceitos. O texto deve ter em mira o desenvolvimento social, cultural e psíquico do aluno, instigando à investigação, promovendo o desenvolvimento da capacidade de estabelecer relações, identificar problemas e descobrir soluções; preferivelmente estimulando a curiosidade e a criatividade. Um bom texto é aquele que apresenta questões abertas e desafios envolvendo a seleção e interpretação de dados provenientes de diferentes fontes. (BRASIL, 1996, p. 131).
\end{abstract}

Ao analisar este critério, nota-se que o documento espera que o livro didático leve em consideração a subjetividade dos alunos no processo de formação dos conceitos e ideias, objetivando o desenvolvimento de capacidades cognitivas como, por exemplo, identificar problemas e descobrir soluções. Um bom livro, segundo o guia, deve dar espaço para as diferentes interpretações de fontes variadas. 
No critério relativo ao desenvolvimento da linguagem, notam-se indicações mais genéricas, ou seja, não direcionada para a aprendizagem histórica.

Os textos devem empregar linguagem adequada ao nível de entendimento do aluno da série a que se destinam. $O$ autor deverá recorrer a diferentes tipos de texto, cuja leitura contribua para enriquecer o vocabulário e o acervo de conhecimentos lingüísticos do aluno, introduzindo termos de uso específico das disciplinas da área, tendo em vista o domínio de suas noções e conceitos. (BRASIL, 1996, p. 132).

O último critério utilizado pelo Guia de 1997 nas avaliações é relativo às atividades e exercícios desenvolvidos nos livros didáticos. Neste critério, fica evidente a indicação de como se ensina História, ou seja, ao apontar como os livros didáticos deveriam organizar suas atividades, notase como o documento espera que o conteúdo deva ser ensinado. Para o guia:

É imprescindível a coerência entre os objetivos, os conteúdos e as atividades. É fundamental que as atividades propostas favoreçam a formação do pensamento, estimulando a observação, a investigação, a análise, a síntese e a generalização. (BRASIL, 1996, p. 132).

Neste critério é explicitado que os livros didáticos disponibilizem atividades que estimulem a observação, a investigação, análise, síntese e a generalização.

Em relação à organização dos conhecimentos, o documento de 2000 defende que o livro didático não deve expor o conhecimento histórico adquiridos de forma fria e mecânica, mas sim levar os alunos a:

[...] desvendar a experiência dos homens vivendo no tempo, em sociedade, e empreender a compreensão ativa da realidade social, a Historia quer ser um elemento de tomada de consciência para as pessoas que a ela se achegam. Assim, o texto deve, de alguma forma, ser capaz de envolver o aluno, considerado como sujeito que tem consciência de estar, a seu modo, fazendo Historia. (BRASIL, 2000, ${ }^{6}$ ).

\footnotetext{
${ }^{6}$ O Guia de Livro Didático de 2000 não foi paginado na parte introdutória, princípios gerais e critérios comuns.
} 
Chamamos a atenção para o indicativo de forma do conteúdo, no entanto o documento não explicita de que forma este texto poderia considerar o aluno como sujeito histórico.

No critério relativo à organização dos conhecimentos, percebe-se um indicativo de como se ensina História, ou seja, o livro deve envolver o aluno ao considerá-lo um sujeito que faz História. Nota-se, a inserção do conceito de consciência no processo de ensino-aprendizagem do conteúdo histórico.

O Guia faz uma distinção entre os critérios adotados na avaliação em Eliminatórios e Classificatórios, neste sentido será realizada a análise dos critérios separadamente. Dentre os critérios Eliminatórios, o documento apresenta quais erros podem desclassificar os livros:

- Conceitos e informações básicas incorretas como anacronismos, voluntarismos e nominalismos.

- Incorreções e inadequações metodológicas como falta de clareza e coerência metodológica.

- Prejuízo à construção da cidadania, ou seja, o livro didático não pode, de forma alguma, expressar preconceito de origem, etnia, gênero, religião, idade ou quaisquer outras formas de discriminação.

Observa-se, nos Critérios Eliminatórios, uma preocupação do Guia em avaliar os livros sob o prisma da cientificidade histórica, ou seja, os mesmos princípios que garantem a rigorosidade metódica da produção historiográfica devem estar presentes na produção dos materiais didáticos evitando, ou buscando evitar, o uso da História para fins meramente políticos e ideológicos. Estes critérios denotam, em algum sentido, uma perspectiva metodológica de proximidade com a ciência de referência.

Em outro critério pode-se encontrar as orientações referentes aos conteúdos que os livros didáticos devem trabalhar. Para o documento, "Os conceitos históricos só se entendem plenamente na sua historicidade; devem ser construídos, portanto, atendendo a esta sua característica" (BRASIL, 2000,). 
Segundo o documento de 2000, a explicitação da opção metodológica do livro didático é ponto importante, "pois manifesta a consciência didáticocientífica do autor e o grau de assimilação a respeito da importância e do lugar da metodologia no trabalho com a História" (BRASIL, 2000). O Guia salienta a importância de os autores demonstrarem a perspectiva teóricometodológica adotada na produção do livro.

Um dos critérios de classificação dos livros didáticos diz respeito ao posicionamento metodológico adotado pelo documento. Neste critério, o Guia aponta que "toda analise histórica deve partir de um problema ou conjunto de problemas, na convicção de que a problematização do passado e do presente constitui o ponto de partida para uma história crítica" (BRASIL, 2000). Esta problematização, de acordo com o documento, deve se relacionar com a realidade do aluno e se adequar a sua capacidade cognitiva.

Para se desenvolver algumas habilidades cognitivas, o documento indica que as atividades e exercícios não devem apenas buscar a realização dos objetivos, mas também estar plenamente integradas aos conteúdos. Consequentemente, as atividades presentes nos livros didáticos devem desenvolver diferentes habilidades estimulando a observação, a investigação, a análise, a síntese, a criatividade, a comparação, a interpretação e a avaliação. (BRASIL, 2000).

Para completar o desenvolvimento das habilidades os textos didáticos complementares devem apresentar uma diversidade de fontes e autores "estimulando a capacidade para debater problemas e produzir texto, com níveis crescentes de complexidade" (BRASIL, 2000,).

O último critério, exposto pelo Guia de Livro Didático, refere-se às orientações destinadas à produção do Manual do Professor. Segundo o documento de 2000, o Manual do Professor deve explicitar os pressupostos teóricos utilizados na produção do Livro, procurando manter coerência com os conteúdos e exercícios elaborados no Livro do Aluno. O Manual do Professor receberá uma melhor avaliação, na medida em que:

[...] oferecer orientação teórica, informações adicionais, bibliografia diversificada, sugestões de leituras e de outros recursos que contribuam para a formação e para a atualização do professor, orientação visando articulação dos 
conteúdos do livro entre si e com outras áreas do conhecimento. Deve conter proposta e discussão sobre avaliação da aprendizagem e sugestões de atividades e de leituras para os alunos. (BRASIL, 2000,).

Observa-se, na apresentação do critério referente à avaliação do Livro do Professor, mais uma indicação de revestir o conteúdo dos livros didáticos de um caráter científico, ou seja, referenciado e transparente em suas posições teóricas.

A partir da análise dos critérios apontados pelo Guia de 2004, observase, claramente, uma orientação metodológica do ensino da História. Segundo o Guia do Livro Didático (BRASIL, 2004, p. 33) o livro deve apresentar coerência entre a proposta da metodologia de ensinoaprendizagem e a elaboração da obra; deve estabelecer relações entre o conhecimento novo e a experiência do aluno, de modo a criar condições para que ele compreenda sua realidade próxima;

O documento, ainda, orienta que o livro necessita contribuir, a partir dos textos e das atividades, para o desenvolvimento de habilidades cognitivas básicas, como observação, investigação, compreensão, argumentação, organização, memorização, análise, síntese, criatividade, comparação, interpretação, avaliação, além da capacidade de debater problemas e de incentivar a produção de textos;

Para o documento, o livro precisa adequar os textos e os exercícios às condições dos alunos, quanto ao grau de complexidade dos conteúdos e quanto à linguagem empregada de acordo com suas possibilidades cognitivas;

E, por final, o Guia orienta que os livros devem disponibilizar textos complementares de diferentes autores, garantindo a perspectiva de que o conhecimento histórico é um espaço de interpretações possíveis, além de sugestões de leitura e de outros instrumentais didáticos que possam ampliar e enriquecer as opções do professor.

Em relação ao uso das fontes históricas nos livros, foi avaliado se estas foram trabalhadas adequadamente, como referencial constitutivo do conhecimento histórico, e se foram convenientemente exploradas, e não 
apenas transcritas, tendo-se o cuidado em resgatar as potencialidades interpretativas dos documentos reproduzidos;

No Guia de 2007, pode-se observar nos critérios que evidenciam o como o conhecimento histórico é construído pelo aluno. Para isso, o livro deve "Pautar-se no entrecruzamento do conhecimento novo, trabalhado em sala de aula, com os conhecimentos advindos da experiência do aluno, levando-o a compreensão da realidade na qual se insere" (BRASIL, 2007, p. 10).

O documento ainda ressalta, a partir dos princípios pedagógicos, a importância que o livro didático deve dar ao desenvolvimento de atividades que potencializem as habilidades cognitivas básicas, como: observação, investigação, compreensão, argumentação, organização, memorização, análise, síntese, criatividade, comparação, interpretação e avaliação. Segundo o documento, o livro deve respeitar as dificuldades próprias de cada aluno, determinando o grau de complexidade e a especificidade do conteúdo a ser ensinado (BRASIL, 2007, p. 11).

Nota-se, também, nos critérios referentes ao Manual do Professor uma perspectiva interdisciplinar, já que o documento orienta o docente a "trabalhar a relação dos conteúdos dos livros, tanto entre si, como com outras áreas do conhecimento, bem como promover discussões acerca das atividades avaliativas das quais se lançara mão". (BRASIL, 2007, p. 11)

Nos critérios referentes aos princípios históricos, o Guia apresenta a importância metodológica de formular, de modo correto, informações e/ou conceitos fundamentais da disciplina histórica, evitando que o aluno apreenda conceitos, informações ou princípios inapropriados e errôneos.

Segundo o documento, é imprescindível que os livros de História considerem a diversidade das tendências e concepções historiográficas, alem de utilizar e adequar "fontes históricas, explorando-as para a compreensão da construção do conhecimento histórico, como complementares ao conteúdo trabalhado" (BRASIL, 2007, p. 11).

A finalidade do estudo da História é uma questão que vem sendo debatida, há algum tempo, por pesquisadores da área de Ensino de História. Algo que se tornou consenso na área acadêmica é que o porquê de 
se aprender História está intimamente relacionado com a perspectiva epistemológica adotada por quem ensina. Portanto, a pergunta foi escolhida como categoria de análise dos critérios de avaliação, presente nos Guias de Livro Didático produzidos pelo PNLD.

Neste sentido, a partir do objetivo de se aprender História, contido na primeira edição do Guia, indica a principal finalidade de se ensinar e aprender História. Para o documento a maneira de se trabalhar o conteúdo histórico, em sala de aula, deve ser adequada às necessidades de formação do cidadão. Sendo assim o livro deve "[...] focalizar situações que envolvam diferentes pontos de vista, colaborar para a formação de noções e conceitos e estimular o exercício da cidadania". (BRASIL, 1996, p. 132).

Na edição seguinte, produzida no ano de 2000, o Guia apresenta novamente o objetivo central da História como sendo

[...] a compreensão dos diferentes processos e sujeitos históricos, das relações que se estabelecem entre os grupos humanos, nos diferentes tempos e espaços, sempre a partir de uma efetiva dimensão de contemporaneidade. A História é um processo de compreensão humana das diversas e múltiplas possibilidades existentes na sociedade, a partir da experiência do presente; portanto, deve possibilitar ao aluno uma compreensão ativa da realidade, condição para o desenvolvimento e para a formação da cidadania. (BRASIL, 2000).

Neste fragmento do Guia, nota-se, no objetivo apresentado, uma perspectiva de se explicar a finalidade da aprendizagem histórica. Neste sentido, o livro didático deve possibilitar, ao aluno, estudar as relações humanas, nos diferentes tempos e espaços, a partir das experiências do presente, tendo como finalidade a compreensão da sua realidade, possibilitando a formação da cidadania.

Um dos aspectos apresentados pelo Guia 2004 refere-se à finalidade de se aprender História, nestes critérios pode-se observar o porquê do estudo da disciplina. De forma geral, o documento orienta que o livro didático auxilie o professor na tarefa de formar o aluno sob os princípios da reflexão sobre a ética, imprescindível ao convívio social, e para a construção da cidadania. Assim sendo, os especialistas avaliaram, nos textos e nas atividades, a existência de uma preocupação do livro em despertar no aluno 
o respeito às diferenças, a prática participativa, o convívio social, a consciência crítica, a tolerância e a liberdade.

No Guia de 2007, observa-se, nos elementos para construção da consciência cidadã, a finalidade de se aprender História. Os critérios apontados pelo Guia orientam que os textos, imagens ou qualquer outro recurso utilizado pelo livro, devem "estar isento de qualquer tipo de conteúdo que expresse preconceitos e discriminação, sejam eles acerca de religião, posicionamento político, etnias, gênero, orientação sexual, condição econômico-social, entre outros" (BRASIL, 2007, p. 13). Segundo o documento, esta atitude de isenção é fundamental para a formação de um cidadão crítico e consciente.

Além de garantir a ausência de conteúdos preconceituosos, o Guia de 2007 estimula "a presença de textos e/ou imagens que levem o educando a observar de forma positiva a participação na sociedade de pessoas com deficiência, mulheres, negros, idosos, crianças, entre outros" (BRASIL, 2007, p. 13).

Partindo desta categoria de análise, observou-se que os documentos analisados expressam, entre si, uma coerência em relação à finalidade da aprendizagem histórica. Fica nítida a orientação dos documentos em relação aos objetivos de ensinar História, ou seja, observa-se, em todos os Guias de Livros Didático, a formação da cidadania como elemento fundamental da aprendizagem histórica, no entanto, o conceito de cidadania é ampliado quando comparamos as diferentes edições.

É possível perceber que o conceito de cidadania, apresentado pelo Guia de 1997, é restrito a um cidadão que "conheça" os conceitos históricos e mobilize diferentes pontos de vista na compreensão de sua realidade social. Nas edições seguintes, verifica-se que este conceito sofre modificações e são características de um cidadão crítico e consciente, o respeito às diferenças, a prática participativa, o convívio social, a consciência crítica, a tolerância e a liberdade. Na última edição analisada, o documento repudia qualquer conteúdo que expresse preconceitos e discriminação religiosa, política, étnica, de gênero, orientação sexual, condição econômico-social, entre outros. 


\section{Considerações Finais}

A partir da análise comparativa dos critérios apresentados pelos Guias de Livro didático, publicados dentre os anos de 1997 e 2007, a pesquisa buscou compreender como foi sendo construída a concepção de ensinoaprendizagem histórica nos anos iniciais. Tomando os princípios referentes ao como ensinar História, pode-se verificar, nas edições investigadas, a presença de aspectos que perpassam todas as edições e que, portanto, influenciaram a produção de livros didáticos no Brasil por dez anos.

O primeiro ponto analisado evidenciou que os conceitos históricos a serem ensinados na disciplina escolar de História, nos anos iniciais, foram previamente constituídos e delimitados, não pelos professores ou a partir das necessidades ou problemas vividos pelos alunos em sala de aula, mas por especialistas a partir de suas concepções teóricas.

A forma como estes conceitos são definidos e apropriados pelos documentos, revelou o que de fato deveria ser aprendido pelos alunos nas escolas. Posto isto, se observa uma tentativa de controle, por parte do Estado, na escolha do que deve ser ensinado e, por consequência, aprendido pelos alunos.

Neste sentido, apesar dos documentos ressaltarem a importância do sujeito histórico no processo de aprendizagem, em relação aos conteúdos históricos, observa-se, nos documentos analisados, uma concepção de aprendizagem histórica alheia às necessidades da vida prática ao sujeito aprendiz, já que os conteúdos propostos não apresentam significado prévio na orientação temporal dos alunos.

Dentre os aspectos relacionados à forma de ensino, pode-se ressaltar a atenção dada pelos documentos ao método de ensino da História baseado na relação entre o conteúdo histórico e as experiências vividas pelos alunos. Esta perspectiva metodológica foi verificada nas orientações pedagógicas e são advindas de teorias psicológicas da aprendizagem. Neste sentido, a aprendizagem é efetivada a partir da subjetivação do conhecimento nas relações com a própria vivência do aluno. 
Outro aspecto evidenciado nas análises dos Guias de Livro didático diz respeito ao desenvolvimento de habilidades cognitivas básicas. Notou-se, ao investigar os documentos, que estas habilidades ou capacidades, como são definidas na primeira edição, foram sendo ampliadas durante as publicações no período pesquisado.

Inicialmente, estas capacidades eram apresentadas como: observação, a investigação, a análise, a síntese e a generalização. Na última edição, analisada estas habilidades cognitivas básicas, foram ampliadas para: observação, investigação, compreensão, argumentação, organização, memorização, análise, síntese, criatividade, comparação, interpretação e avaliação. Complementando estas habilidades, os Guias orientam que os livros didáticos devem proporcionar, aos alunos, atividades que os levem a identificar e resolver problemas.

Presentes em todas as edições analisadas e descritas pelos Guias como princípios pedagógicos, verificou se que estas habilidades cognitivas, apresentadas como critério avaliativo das coleções de livros didáticos, foram escolhidas como o principal recurso metodológico para o ensino da História. Neste sentido, pode se afirmar que apesar de as habilidades cognitivas básicas serem utilizadas no ensino de outras disciplinas, também são indicadas para ensinar História.

Os Guias investigados defendem que as coleções apresentem, de forma clara, suas posições teóricas e metodológicas. Sendo assim, além dos princípios pedagógicos, os Guias também apresentaram, de forma reduzida, princípios históricos referentes ao ensino-aprendizagem da disciplina. Dentre estes princípios, pode se ressaltar o método de trabalho com fontes. Segundo os documentos, as fontes devem ser diversificadas e trabalhadas de forma contextualizada, e não apenas transcritas, utilizando as potencialidades interpretativas dos documentos reproduzidos nos livros.

De forma menos explícita que os demais princípios, os Guias defendem uma perspectiva de ensino da História baseada na problematização do passado e do presente, como ponto de partida para a aprendizagem de uma Historia crítica. Apesar de indicar que esta problematização deve ter relação com a realidade do aluno e se adequar a sua capacidade cognitiva, os 
documentos não demonstram em seus princípios que estes problemas devam partir das experiências dos alunos, mas estarem relacionados com a realidade deles.

Pode-se afirmar que o encaminhamento metodológico adotado pelos Guias, está bastante próximo da concepção teórico-educacional histórico cultural da aprendizagem, apresentada por Libâneo (2008). Os documentos apresentam uma proposta de formação crítica em relação à diversidade sociocultural, estabelecendo uma relação entre presente e passado.

Entretanto, analisando os princípios da aprendizagem propostos pelos Guias, nota-se que a aprendizagem histórica fica restrita à própria atividade de aprender. Desta maneira, com base nos conteúdos da disciplina de História, aprender História significa desenvolver capacidades e habilidades para que os alunos aprendam por si mesmos, buscando soluções gerais para questões específicas e, assim, aplicarem nas situações concretas.

Para os documentos investigados, a aprendizagem ocorre a partir do desenvolvimento das habilidades cognitivas, ou seja, capacidades de analisar os conteúdos. Segundo Libâneo (2008), o pensamento teórico dos alunos caracteriza a essência e o desenvolvimento dos conteúdos e, com isso, os alunos adquirem os métodos e estratégias cognoscitivas gerais de cada ciência, em função de analisar e intervir nas situações concretas da vida prática.

Em relação a função do ensino de História, pode-se perceber dentre os objetivos da aprendizagem histórica, apontados pelos documentos, que 0 estudo das diversas e múltiplas realidades existentes na sociedade, a partir da experiência do presente, deve possibilitar ao aluno uma compreensão ativa de seu meio social, tornando este sujeito um cidadão crítico e consciente, tolerante e participativo, ético e livre.

Nota-se, que a formação deste cidadão representado pelos documentos está mais próxima de uma discussão jurídica de direitos e deveres constitucionais do que propriamente em uma discussão educacional ou histórica.

Apesar de os documentos apresentarem como a principal finalidade da aprendizagem histórica a formação deste cidadão exposto acima, não é 
esclarecido, por exemplo, como o estudo das diferentes realidades, temporalidades e sujeitos contribuem para a formação deste cidadão.

Neste sentido, tem se a impressão que este é um processo linear, automático e inquestionável. Em nenhum momento o documento considera que a aprendizagem histórica pode ser dialética, ou seja, apesar de viverem em um mesmo país, a realidade dos alunos não é única e, muitas vezes, seus direitos são desprezados pelo próprio Estado.

Na tentativa de responder as questões elencadas anteriormente, podese afirmar que a construção da Didática da História específica para os anos iniciais foi feita não a partir de uma concepção única de ensinoaprendizagem, mas do diálogo entre várias perspectivas teóricas e metodológicas. Neste sentido, cabe ressaltar que, em uma análise ampliada desta didática específica, o processo de ensino-aprendizagem da História foi desmembrado em diferentes "etapas".

A partir dos pressupostos e significados teóricos e metodológicos de uma Didática da História específica para os anos iniciais pode-se concluir que, a partir de seu percurso de constituição, houve um processo de segmentação das dimensões do ensino e, por conseguinte da aprendizagem Histórica. Esta fragmentação foi forjada pela pluralidade de concepções teóricas e metodológicas presentes na construção dos princípios de como,

o que e por que ensinar História. Neste processo, é possível afirmar que nesta concepção didática específica para os anos iniciais, o processo de ensino-aprendizagem da História, foi fragmentado e instrumentalizado pela diversidade de concepções envolvidas nesta produção.

Esta fragmentação foi verificada no processo de consolidação de uma Didática da História presente nos documentos oficiais, que orientam o ensino e a aprendizagem nos anos iniciais. Neste processo de consolidação, primeiramente pensou-se na escolha do conteúdo, a partir de uma visão historiográfica, em seguida buscou-se nas teorias pedagógicas e psicológicas formas e métodos de ensino deste conteúdo e, por fim, definiuse, como finalidade deste processo, a formação de um cidadão consciente de seus direitos e deveres, apto a viver em sociedade. 
Cabe ressaltar, que nas análises não foram encontradas nenhuma referência ao aspecto dialético da aprendizagem histórica, ou seja, os conteúdos, os métodos e finalidades da aprendizagem histórica foram constituídos hermeticamente em razão de suas perspectivas epistemológicas.

Pode-se concluir, portanto, que no percurso de constituição desta didática específica não foi levado em consideração o fato de que o método de ensino da História "pressupõe uma relação intrínseca com o método e a filosofia da própria ciência, o qual delimita, não somente os objetivos e finalidades do ensino, mas também a sua forma de ensinar" (SCHMIDT, 2006, p. 4107).

A partir destes resultados, obtidos nas análises de documentos brasileiros, é possível perceber a necessidade de se retomar para os processos didáticos, a reflexão sobre as formas e funções da História como ciência de orientação da vida prática.

\section{Referências}

BRASIL. Fundo Nacional de Desenvolvimento da Educação. Edital de convocação para inscrição no processo de avaliação e seleção de obras didáticas a serem incluídas no guia de livros didáticos de $1^{a}$ a $4^{a}$ série do PNLD/2007. Brasília: MEC/SEB, 2004b.

BRASIL. Ministério da Educação. Guia de Livros Didáticos PNLD 1997: História. Brasília: MEC, 1996.

BRASIL. Ministério da Educação. Guia de Livros Didáticos PNLD 2001: História. Brasília: MEC, 2000.

BRASIL. Ministério da Educação. Guia de Livros Didáticos PNLD 2005: História. Brasília: MEC, 2004.

BRASIL. Ministério da Educação. Guia de Livros Didáticos PNLD 2008: História. Brasília: MEC, 2007.

BRASIL. Ministério da Educação. Plano Decenal de Educação para Todos. Brasília: MEC, 1993.

FRANCO, Maria P.B. Análise de conteúdo. 2. ed. Brasília: Líber Livro, 2005. LIBÂNEO, José C. Didática e epistemologia: para além do embate entre a didática e as didáticas específicas. In: VEIGA, Ilma Passos A.; D’ÁVILA, 
Cristina (org.). Profissão docente: novos sentidos, novas perspectivas. Campinas: Papirus, 2008. p. 59-88.

SCHMIDT, Maria Auxiliadora. Contribuições ao estudo da construção da didática da história como disciplina escolar no Brasil: 1935-1952. In: CONGRESSO LUSO-BRASILEIRO DE HISTÓRIA DA EDUCAÇÃO, 6., 2006, Uberlândia. Anais... Uberlândia: UFU, 2006. p.4100-4109. Disponível em: www.faced.ufu.br/colubhe06/anais/ arquivos/eixo6.htm. Acesso em: 12 nov. 2011. 